\title{
The effect of benzydamine hydrochloride on preventing postoperative sore throat after total thyroidectomy: a randomized-controlled trial
}

\section{Effet du chlorhydrate de benzydamine sur la prévention des maux de gorge postopératoires après une thyroïdectomie totale : une étude randomisée contrôlée}

\author{
Doyeon Kim, MD • Heejoon Jeong, MD • Jihye Kwon, MD • Sehee Kang, MD • Bobae Han, MD • \\ Eun Kyung Lee, MD • Sangmin M. Lee, MD, PhD • Ji Won Choi, MD, PhD
}

Received: 27 March 2018/Revised: 23 January 2019/Accepted: 28 January 2019/Published online: 16 April 2019

(c) Canadian Anesthesiologists' Society 2019

\begin{abstract}
Purpose We compared the effects of benzydamine hydrochloride (BH), $10 \%$ lidocaine, and normal saline spray on preventing postoperative sore throat (POST) in patients who underwent total thyroidectomy (TT).

Methods In this prospective, randomized, parallel-group, double-blind study, the incidence of POST at six hours after tracheal extubation was compared among three groups as a primary outcome. American Society of Anesthesiologists physical status I-II patients undergoing elective TT under general anesthesia were enrolled. Patients were randomly stratified into group $C(n=33$, normal saline), group $L$ ( $n=33,10 \%$ lidocaine), or group $B(n=33,0.3 \% \mathrm{BH})$. The participants, caregiver, and investigator were blinded to group assignment. Each study drug was sprayed three times on the endotracheal tube (ETT) cuff ten seconds before intubation. Incidence and severity of POST were recorded within $24 \mathrm{hr}$ postoperatively (during postanesthesia care unit stay, and at six, 12, and $24 \mathrm{hr}$ after extubation). $P$ values were adjusted for multiple comparisons.
\end{abstract}

Doyeon Kim and Heejoon Jeong contributed equally as co-first authors.

D. Kim, MD $\cdot$ H. Jeong, MD $\cdot$ J. Kwon, MD $\cdot$ S. Kang, MD .

B. Han, MD - E. K. Lee, MD - S. M. Lee, MD, PhD .

J. W. Choi, MD, PhD ( $($ )

Department of Anesthesiology and Pain Medicine, Samsung Medical Center, Sungkyunkwan University School of Medicine, 81 Irwon-ro, Gangnam-gu, Seoul 06351, Republic of Korea e-mail: jiwon0715.choi@samsung.com
Results Ninety-nine patients were enrolled. Eighty-seven patients completed the study. The incidence of POST at six hours after tracheal extubation was similar among the three groups (group C: 31 [93.9\%], group L: 29 [87.9\%], and group B: 27 [81.8\%]; $P=0.38$ ). Nevertheless, the incidence of POST was significantly different among the three groups at 12 and $24 \mathrm{hr}$ after TT (12 hr: $P=0.002,24$ hr: $P=0.01)$. The severity of POST after tracheal extubation was statistically different among the study groups (6 hr: $P=0.04,12 \mathrm{hr}: P=0.01)$. No adverse effects were observed.

Conclusion Application of BH spray on the ETT cuff reduced the incidence and severity of POST at $12 \mathrm{hr}$ after TT. We suggest this method to be a non-invasive and effective management option for POST without serious side effects.

Trial registration Clinical Research Information Service (KCT0002627); registered 24 November, 2017.

\section{Résumé}

Objectif Nous avons comparé les effets de la vaporisation de chlorhydrate de benzydamine (CB), de lidocaïne $10 \%$, ou de solution saline sur la prévention des maux de gorge postopératoires chez les patients subissant une thyrö̈dectomie totale (TT).

Méthode Dans cette étude prospective, randomisée, en parallèle et à double insu, l'incidence des maux de gorge postopératoires six heures après l'extubation trachéale a été comparée dans trois groupes pour répondre à notre critère d'évaluation principal. Des patients de statut physique I-II selon l'American Society of Anesthesiologists et subissant une TT non urgente sous 
anesthésie générale ont été recrutés. Les patients ont été aléatoirement alloués au groupe $C(n=33$, solution saline), au groupe $L$ ( $n=33$, lidocaïne $10 \%)$, ou au groupe $B(n=33, C B \quad 0,3 \%)$. Les participants, anesthésistes et chercheurs ne connaissaient pas l'allocation de groupe. Chaque médicament étudié était vaporisé trois fois sur le ballonnet du tube endotrachéal (TET) dix secondes avant l'intubation. L'incidence et la gravité des maux de gorge postopératoires ont été enregistrées dans les 24 heures postopératoires (pendant le séjour en salle de réveil, et à six, 12 et 24 h après l'extubation). Les valeurs $P$ ont été ajustées pour tenir compte des comparaisons multiples.

Résultats Quatre-vingt-dix-neuf patients ont été recrutés. Quatre-vingt-sept patients ont terminé l'étude. L'incidence des maux de gorge postopératoires à six heures après l'extubation trachéale était semblable dans les trois groupes (groupe C: 31 [93,9 \%], groupe L: 29 [87,9\%], et groupe B: 27 [81,8\%]; $P=0,38)$. Toutefois, l'incidence de maux de gorge postopératoires était significativement différente entre les trois groupes à 12 et $24 \mathrm{~h}$ après la TT (12 $h: P=0,002,24 h: P=0,01)$. La gravité des maux de gorge postopératoires après l'extubation trachéale était différente d'un point de vue statistique entre les groupes à l'étude $(6 \mathrm{~h}: P=0,04,12$ $h: P=0,01)$. Aucun effet secondaire indésirable n'a été observé.

Conclusion Le recours à une vaporisation de chlorhydrate de benzydamine sur le ballonnet du tube endotrachéal a réduit l'incidence et la gravité des maux de gorge postopératoires à $12 h$ après une thyrö̈dectomie totale. Selon nos résultats, cette méthode constitue une option de prise en charge non invasive et efficace des maux de gorge postopératoires sans effets secondaires importants.

Enregistrement de l'étude Clinical Research Information Service (KCT0002627); enregistrée le 24 novembre 2017.

Postoperative sore throat (POST) is a common complication following general anesthesia. A previous study demonstrated that even patients who were intubated for only a short duration sustained laryngeal trauma. ${ }^{1}$ In addition to upper airway instrumentation, numerous factors contribute to POST, such as the number of intubation attempts, the diameter of the endotracheal tube (ETT), and ETT cuff pressure and design. ${ }^{2,3}$ Although several studies have attempted to find ways to decrease POST, it remains a major contributing factor to patient dissatisfaction after tracheal intubation.
Postoperative sore throat is more common and severe in patients undergoing thyroidectomy compared to any other surgery. In fact, several studies have shown the incidence of sore throat after thyroid surgery to be more than $60 \%{ }^{4-6}$ The thyroid is located adjacent to the trachea; thus, movement of the ETT during a surgical procedure was suggested as the main contributor to the increased incidence of POST after thyroidectomy. ${ }^{4}$ In addition, surgical manipulation of the thyroid directly compresses the trachea and affects the ETT cuff pressure. ${ }^{7}$ The mechanism of POST after thyroidectomy may also be associated with regional mucosal trauma, laryngeal edema, or vocal cord hematoma.

Benzydamine hydrochloride $(\mathrm{BH})$ is a well-known topical non-steroidal anti-inflammatory drug (NSAID) ${ }^{8}$ that effectively reduces symptoms associated with clinical inflammation. Studies have shown the POST alleviation effect of BH. ${ }^{9-13}$ In particular, a recently published metaanalysis concluded that topical $\mathrm{BH}$ was associated with decreased incidence of POST compared with non-analgesic and lidocaine control groups. Nevertheless, the ability of $\mathrm{BH}$ placed around the ETT cuff to prevent severe POST was limited. ${ }^{14}$ In addition, a few studies have examined the risk of POST in thyroidectomy using some pharmacologic prophylactic options. Estebe et al., for example, evaluated the efficacy of alkalinized lidocaine to reduce POST in patients who underwent total thyroidectomy (TT). ${ }^{15}$ To our knowledge, no study has investigated the effectiveness of topical $\mathrm{BH}$ to attenuate POST after extensive thyroidectomy.

Therefore, the aim of this study was to compare the incidence of POST at six hours after tracheal extubation among $\mathrm{BH}, 10 \%$ lidocaine, and normal saline groups who underwent TT.

\section{Methods}

Patient and study design

This prospective, randomized, parallel-group, double-blind study was designed to demonstrate the superiority of $\mathrm{BH}$ and was approved by the Institutional Review Board (IRB) of Samsung Medical Center, Seoul, Republic of Korea (IRB no. 2016-11-110). The study was registered with the Clinical Research Information Service (registration no. KCT0002627).

Adult patients undergoing elective TT under general anesthesia from February 2017 to July 2017 were assessed for eligibility. Written informed consent was obtained from all patients who participated in the study. Patients with a 
history of preoperative sore throat or hoarseness, symptoms of upper respiratory infection within two weeks, allergy to NSAIDs or lidocaine, a difficult airway (requiring more than two attempts of endotracheal intubation), American Society of Anesthesiologists (ASA) physical status IV, obesity (body mass index [BMI] $>30 \mathrm{~kg} \cdot \mathrm{m}^{-2}$ ), pregnancy, severe liver disease or kidney function disorder, and/or significant arrhythmia or cardiovascular disease were excluded from the present study.

Drug preparation, blinding, and randomization

After enrolment (by D.K. and H.J.), all patients were randomly allocated to one of three groups using a computergenerated program (Random Allocation Software version 1.0; Informer Technologies, Los Angeles, CA, USA) with the random permuted block method (1:1:1 allocation ratio and a block size of 3). Group assignment using a randomization sequence-ensured by way of consecutively numbered, opaque, sealed envelopes-was conducted by one of the authors (J.K.) who was not involved in either anesthetic management or outcome assessment by opening each envelope in sequence. The three bottles of spray were prepared to have the same external appearance, and each was labelled with the number 1, 2, or 3 (by S.K.).

The group allocation was as follows:

- Group C ( $n=37)$ : the ETT cuffs were sprayed three times with normal saline (approximately $0.3 \mathrm{~mL}$ ) as a control group.

- Group L $(n=38)$ : the ETT cuffs were sprayed three times with $10 \%$ lidocaine spray (Veracaine spray, SKpharm, Korea), which contained approximately 30 $\mathrm{mg}$ of lidocaine hydrochloride.

- Group B $(n=38)$ : the ETT cuffs were sprayed three times with $0.3 \%$ BH spray $\left(\right.$ Difflam $^{\mathrm{TM}}$ spray, NMpharm, Korea), which contained approximately $0.9 \mathrm{mg}$ of $\mathrm{BH}$.

\section{Study protocols}

The study participants were not pretreated with any medicine, and standard monitors were used in the operating room, including electrocardiogram, pulse oximetry, non-invasive arterial blood pressure, nasopharyngeal temperature, and end-tidal carbon dioxide, which was maintained between 30 and $35 \mathrm{mmHg}$. Anesthesia was induced with thiopental sodium $(3 \sim 6$ $\left.\mathrm{mg} \cdot \mathrm{kg}^{-1}\right)$, rocuronium $\left(0.8 \mathrm{mg} \cdot \mathrm{kg}^{-1}\right)$, and fentanyl $(0.5$ $\left.\mu \mathrm{g} \cdot \mathrm{kg}^{-1}\right)$. All of the study drugs were sprayed three times on the ETT cuff at ten seconds before intubation by one of the authors blinded to the treatment (B. H.). Intubations were performed by attending anesthesiologists who were blinded to the medication of our research, using an ETT (Mallinckrodt Pharmaceuticals, Staines-upon-Thames, UK) measuring $7.0 \mathrm{~mm}$ and $8.0 \mathrm{~mm}$ in internal diameter for females and males, respectively. The cuff was inflated with air, and the cuff pressure was measured by a cuff pressure gauge (VBM Medizintechnik $\mathrm{GmbH}$, Sulz am Neckar, Germany). To maintain a level of $20 \mathrm{cmH}_{2} \mathrm{O}$ to 25 $\mathrm{cmH}_{2} \mathrm{O}$, intracuff pressure was monitored every $30 \mathrm{~min}$. Anesthesia was maintained with sevoflurane 2-3 vol\%. Subjects were ventilated with oxygen and medical air $\left(\mathrm{F}_{\mathrm{I}} \mathrm{O}_{2}\right.$ of 0.6). When skin suture was started, $0.5 \mu \mathrm{g} \cdot \mathrm{kg}^{-1}$ of fentanyl was administered to patients to relieve postoperative pain. At the end of surgery, pyridostigmine and glycopyrrolate were administered to prevent residual neuromuscular block. Tracheal extubation was performed after gentle suctioning of the oral cavity when patients were fully awake and obeying commands. Patients were subsequently transferred to the postanesthesia care unit (PACU).

We recorded patient age, gender, height, weight, BMI, smoking history, modified Mallampati grade in the sitting position, Cormack-Lehane view, duration of operation and anesthesia, and any side effects associated with the study drugs (e.g., cough, dry mouth, burning sensation, and local numbness). Following surgery, patients with pain severity greater than a verbal rating scale (VRS) score of 4 were treated with $0.5 \mu \mathrm{g} \cdot \mathrm{kg}^{-1}$ of fentanyl intravenously in the PACU and $30 \mathrm{mg}$ of ketorolac IV in the ward before oral ingestion. The total amounts of fentanyl and ketorolac for postoperative pain were also monitored.

Postoperative sore throat was scored at $30 \mathrm{~min}$ (at PACU) and at six, 12, and $24 \mathrm{hr}$ after tracheal extubation by an anesthesiologist who was unaware of the group allocation. POST was assessed using a 0-10 VRS score, with $0=$ no pain and $10=$ worst imaginable pain. We educated the subjects on the differences in pain related to endotracheal intubation and thyroidectomy to distinguish them. Pain in the surgical region was described as sharp and stabbing pain due to the skin incision and suture, while pain caused by POST originated from the inside of throat and was similar to the discomfort of a cold. Potential adverse effects associated with study drugs, such as numbness, hoarseness, nausea/vomiting, dry mouth, and stinging sensation were also noted. Acetaminophen $650 \mathrm{mg}$ was routinely administrated per os to the patients in the general surgery department every eight hours starting with the first postoperative day 1 .

Statistical analysis

The primary outcome of this study was the incidence of POST at six hours after TT. The secondary outcomes were severity of POST (especially at six, 12, and $24 \mathrm{hr}$ ) and cumulative amount of opioid consumption within $24 \mathrm{hr}$ 
after TT. A power calculation was based on a previous study that identified the incidence of POST following tracheal intubation after spraying $2 \%$ lidocaine (40.8\%), normal saline $(53.7 \%)$, and $3 \% \mathrm{BH}(17 \%) .{ }^{9}$ To detect a statistically significant difference in incidence of POST at six hours after TT among the three groups, we used the Chi-square test. With a power of 0.8 and an alpha error of $0.05,33$ patients in each group were required. Assuming a $10 \%$ dropout rate, we planned to enroll at least 111 patients (37 subjects for each group).

Categorical variables were presented as numbers (percentages), while continuous variables including demographic data and the severity of POST among three study groups were presented as mean (standard deviation [SD]).

Pearson's Chi-square test was used to analyze the differences in incidence among study groups $6 \mathrm{hr}, 12 \mathrm{hr}$, and $24 \mathrm{hr}$ after TT. Partitioning Chi-square test was applied for multiple pairwise comparisons and $P$ values were adjusted by multiplying by three. To reduce the impact of the outliers, we compared the severity of POST using the Kruskal-Wallis test. Furthermore, Bonferroni correction was used to compare the differences among groups and $P$ values were multiplied by four for the adjustment. For the adjustment of pairwise comparisons, Bonferroni and Tukey correction were used and $P$ values were multiplied by three. The cumulative amount of opioid during $24 \mathrm{hr}$ after TT was analyzed by analysis of variance. Statistical analysis was performed using SPSS version 20 (IBM Corp., Armonk, NY, USA) and $P<0.05$ was considered to be statistically significant.

\section{Results}

As we needed 111 participants, 137 patients were recruited from February 2017 to July 2017. Among them, 16 patients who did not meet the inclusion criteria were excluded and eight withdrew from the study; the remaining 113 patients were randomly assigned to three groups. Fourteen patients were subsequently excluded because of intubation difficulties (two cases), transition to lobectomy (eight cases), lack of PACU records (three cases), and prolonged anesthesia (one case). Notably, we decided to exclude the one case with anesthesia lasting more than four hours based on the findings of a previous study suggesting increased risk of POST associated with prolonged anesthesia. ${ }^{4}$ Thus, 99 patients were finally analyzed (Figure). The trachea were intubated in a single attempt in all these patients.

Patient characteristics are shown in Table 1. Age, BMI, gender, ASA physical status, history of underlying disease or smoking, and surgery were comparable among the groups (Table 1). Intraoperative vital signs and use of vasopressors were not different among the three groups.

Incidence of POST at $6 \mathrm{hr}$ after tracheal extubation (the primary outcome) was comparable among the groups (group C, 31 [93.9\%]; group L, 29 [87.9\%]; group B, 27 [81.8\%], $P=0.38$ ). Nevertheless, the incidence of POST was significantly different among the three groups at 12 and $24 \mathrm{hr}(12 \mathrm{hr}: P=0.002,24 \mathrm{hr}: P=0.01)$ (Table 2). After six hours and $12 \mathrm{hr}$ of tracheal extubation, the severity of POST was significantly decreased in group B compared with group C. Furthermore, at $12 \mathrm{hr}$, the POST severity in group B was also lower than that of group L

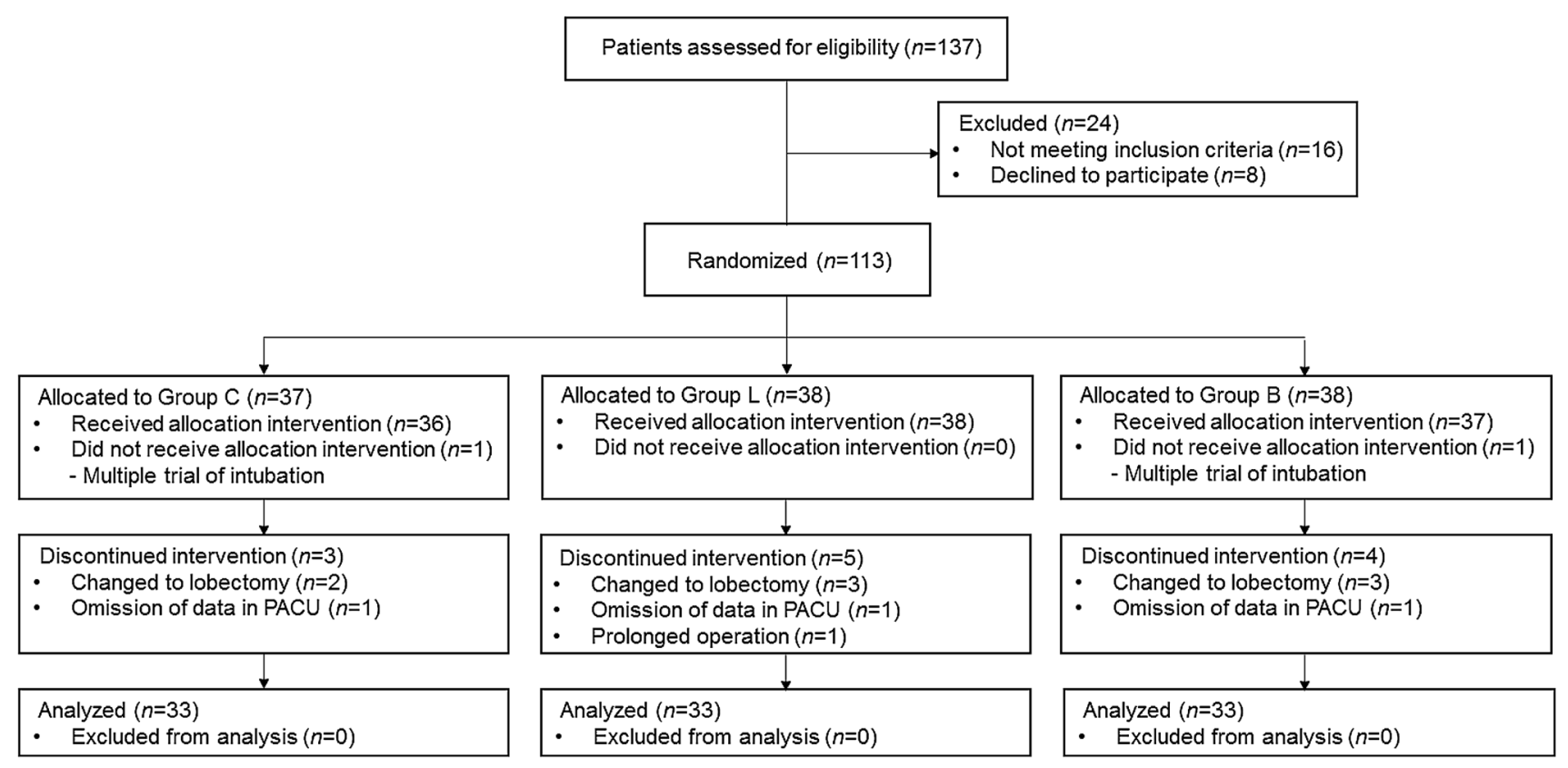

Figure CONSORT diagram 
Table 1 Demographic data

\section{Group}

$\mathrm{C}(n=33)$

$\mathrm{L}(n=33)$

B $(n=33)$

Demographics

Age (yr)

Gender (female/male)

$46(10)$

$24(73 \%) / 9(27 \%)$

Height $(\mathrm{cm})$

$163(9)$

Weight $(\mathrm{kg})$

66 (11)

BMI $\left(\mathrm{kg} \cdot \mathrm{m}^{-2}\right)$

25 (2)

$24(73 \%)$

$9(27 \%)$

$4(12 \%)$

Smoking habit (yes)

Airway evaluation

Mallampati

1

2

3

Cormack-Lehane view

$$
1
$$

2

3

Diagnosis

Papillary thyroid cancer

Grave's disease

Multiple benign tumours

Follicular neoplasm of thyroid

Type of surgery

TT + CND, both

$\mathrm{TT}+\mathrm{CND}, \mathrm{Rt}$

$\mathrm{TT}+\mathrm{CND}, \mathrm{Lt}$

$11(33 \%)$

$16(49 \%)$

$6(18 \%)$

$13(39 \%)$

$16(49 \%)$

$4(12 \%)$

$31(94 \%)$

0

0

0

$16(49 \%)$

0

TT

$2(6 \%)$

$2(6 \%)$

$12(36 \%)$

$1(3 \%)$

$182(70)$

47 (12)

$45(16)$

$21(64 \%) / 12(36 \%)$

163 (9)

$161(9 \%)$

64 (15)

$161(9)$

24 (3)

63 (11)

24 (3)

$20(61 \%)$

$20(61 \%)$

$13(39 \%)$

$13(39 \%)$

$3(9 \%)$

0

$7(21 \%)$

$7(21 \%)$

$18(55 \%)$

$20(61 \%)$

$8(24 \%)$

$6(18 \%)$

$9(27 \%)$

$12(36 \%)$

$22(67 \%)$

$17(52 \%)$

$2(6 \%)$

$4(12 \%)$

$24(73 \%)$

$26(79 \%)$

$5(15 \%)$

$1(3 \%)$

$2(6 \%)$

$3(9 \%)$

$2(6 \%)$

TT + CND \& Rt./Lt. lateral neck dissection

$\mathrm{TT}+\mathrm{mRND}$, both

Duration of anesthesia (min)
$18(55 \%)$

$14(42 \%)$

$1(3 \%)$

$3(9 \%)$

$6(18 \%)$

$7(21 \%)$

$2(6 \%)$

$166(77)$

Note: Data are given as $n(\%)$ or mean (SD). $n=$ number of patients

ASA = American Society of Anesthesiologists physical status; BMI = body mass index; CND = central neck dissection; mRND = modified radical neck dissection; $\mathrm{SD}=$ standard deviation; $\mathrm{TT}=$ total thyroidectomy

(group B vs group C: six hours, $P=0.01$, and $12 \mathrm{hr}, P=$ 0.001; group B vs group L: six hours, $P=0.10$ and $12 \mathrm{hr}, P$ $=0.01 ; P$ values were adjusted by Bonferroni correction) (Table 3). In addition, the cumulative amount of opioid as a postoperative analgesic was not statistically different among the study groups $(P=0.78)$.

None of the participants experienced systemic or local side effects including hoarseness, numbness, nausea/ vomiting, or stinging sensation considered to be related to the study drugs.

\section{Discussion}

Our results demonstrated that administration of $\mathrm{BH}$ spray to the ETT cuff did not reduce the incidence of POST six hours after tracheal extubation. Nevertheless, after $12 \mathrm{hr}$, the incidence and the severity of POST were significantly decreased in the $\mathrm{BH}$ group compared with the $10 \%$ lidocaine and normal saline groups (Tables 2, 3). Furthermore, applying $10 \%$ lidocaine sustained the incidence of POST at $24 \mathrm{hr}$. 
Table 2 Incidence of postoperative sore throat in control (C), lidocaine (L) and benzydamine hydrochloride (B) groups

\begin{tabular}{|c|c|c|c|c|}
\hline & \multicolumn{3}{|l|}{ Group } & \multirow[t]{2}{*}{$P$} \\
\hline & $\mathrm{C}(n=33)$ & $\mathrm{L}(n=33)$ & $\mathrm{B}(n=33)$ & \\
\hline $6 \mathrm{hr}$ & $31(94 \%)$ & $29(88 \%)$ & $27(82 \%)$ & $>0.99^{\wedge}$ \\
\hline B vs C & & & & $0.33^{\wedge \wedge}$ \\
\hline B $v s \mathrm{~L}$ & & & & $>0.99^{\wedge \wedge}$ \\
\hline $\mathrm{C} v s \mathrm{~L}$ & & & & $>0.99^{\wedge \wedge}$ \\
\hline $12 \mathrm{hr}$ & $26(79 \%)$ & $24(73 \%)$ & $13(39 \%)$ & $0.01^{\wedge}$ \\
\hline B vs C & & & & $0.003^{\wedge \wedge}$ \\
\hline B $v s \mathrm{~L}$ & & & & $0.02^{\wedge \wedge}$ \\
\hline $\mathrm{C} v s \mathrm{~L}$ & & & & $>0.99^{\wedge \wedge}$ \\
\hline $24 \mathrm{hr}$ & $10(30 \%)$ & $21(64 \%)$ & $11(33 \%)$ & $0.04^{\wedge}$ \\
\hline B vs C & & & & $>0.99^{\wedge \wedge}$ \\
\hline B $v s \mathrm{~L}$ & & & & $0.04^{\wedge \wedge}$ \\
\hline C vs $\mathrm{L}$ & & & & $0.02^{\wedge \wedge}$ \\
\hline
\end{tabular}

Values are expressed as number $(\%)$

${ }^{\wedge} P$ value, analysis of Pearson Chi-square test

$P$ values were multiplied by three, according to the time-period, for the adjustment

${ }^{\wedge} P$ value, analysis of multiple comparisons by partitioning of the Chi-square method

$P$ values were multiplied by three for the adjustment of pairwise comparisons

Group C: spraying normal saline as a control group

Group L: spraying $10 \%$ lidocaine hydrochloride

Group B: spraying $0.3 \%$ benzydamine hydrochloride

Several factors contribute to POST. Inflammation and irritation of the respiratory mucosa trigger POST and cough after anesthesia with dry inhalant agents. ${ }^{16}$ Kuriyama et al. demonstrated that corticosteroids applied to the ETT effectively mitigate the incidence of POST $v s$ non-analgesic controls or lidocaine in a systemic review. ${ }^{17}$ This finding is in line with our results and supports the idea that POST may be related to increased inflammatory mediators. ${ }^{18}$ Furthermore, BH is a NSAID that is used both systemically and topically. NSAIDs act peripherally to attenuate the production of prostaglandins that sensitize nerve endings at the site of damage. ${ }^{19}$ These effects originate from inhibition of the cyclooxygenase enzyme that converts arachidonic acid from the phospholipid membrane by phospholipases to prostaglandins. ${ }^{20}$ Therefore, BH may play a defensive role in an inflammatory state.

Sironi et al. investigated the effect of BH on cytokine production in both in vivo and in vitro conditions. ${ }^{21}$ They reported that $\mathrm{BH}$ inhibited the production of tumour necrosis factor alpha in a study of Candida vaginitisis. Benzydamine hydrochloride also has potency against lipopolysaccharide (LPS)-induced toxicity ${ }^{22}$ : an experimental study demonstrated the therapeutic efficacy of $\mathrm{BH}$ in managing endotoxic shock induced by LPS administration.

Baldock et al. showed the peak plasma concentration of BH at approximately six hours after local application. ${ }^{23}$ In the present investigation, we administered the study drugs immediately prior to endotracheal intubation based on the results of previous research. ${ }^{11}$ Subjects in our study groups demonstrated a high incidence of POST at six hours after tracheal extubation. Nevertheless, the incidence and severity of POST in the BH group were significantly lower than in the other two groups. Our results suggest that BH suppresses the response of inflammatory mediators and may reduce POST incidence and severity for longer periods than normal saline or $10 \%$ lidocaine.

In the research design period, we tried to evaluate the effects of BH on the incidence of POST via a topical agent sprayed on the ETT cuff. Systemic administration of study drugs might be difficult to apply to all patients under the same conditions or at the same time. Therefore, we selected BH and other study drugs in a uniform formulation that could be sprayed on the ETT cuff. Moreover, a previous study that evaluated the pharmacokinetics of BH in healthy volunteers demonstrated that the plasma concentrations of $\mathrm{BH}$ after vaginal douching and washing of the oral cavity were lower than in gastrointestinal absorption after 
Table 3 Severity of POST for the study groups by time-point

\begin{tabular}{|c|c|c|c|c|c|c|c|}
\hline \multirow[t]{2}{*}{ Time } & \multicolumn{3}{|l|}{ Group } & \multirow[t]{2}{*}{ Mean differences } & \multirow[t]{2}{*}{ SD } & \multirow[t]{2}{*}{$P$} & \\
\hline & $\mathrm{C}(n=33)$ & $\mathrm{L}(n=33)$ & $\mathrm{B}(n=33)$ & & & & \\
\hline 30 min (at PACU) & $3.1(1.5)$ & $3.2(2.1)$ & $2.7(2.1)$ & & & $>0.99^{\mathrm{b}}$ & \\
\hline $\mathrm{B}$ vs $\mathrm{C}$ & & & & -0.3 & 0.5 & $>0.99^{\mathrm{a}}$ & $>0.99^{c}$ \\
\hline B $v s \mathrm{~L}$ & & & & -0.3 & 0.5 & $>0.99^{\mathrm{a}}$ & $>0.99^{c}$ \\
\hline $\mathrm{C} v s \mathrm{~L}$ & & & & 0 & 0.5 & $>0.99^{\mathrm{a}}$ & $>0.99^{c}$ \\
\hline $6 \mathrm{hr}$ & $4.0(2.0)$ & $3.5(2.1)$ & $2.5(1.6)$ & & & $0.04^{\mathrm{b}}$ & \\
\hline $\mathrm{B} v s \mathrm{C}$ & & & & -1.6 & 0.5 & $0.02^{\mathrm{a}}$ & $0.25^{\mathrm{c}}$ \\
\hline $\mathrm{B} v s \mathrm{~L}$ & & & & -1 & 0.5 & $0.40^{\mathrm{a}}$ & $0.33^{\mathrm{c}}$ \\
\hline C vs L & & & & 0.6 & 0.5 & $>0.99^{\mathrm{a}}$ & $>0.99^{c}$ \\
\hline $12 \mathrm{hr}$ & $2.7(1.8)$ & $2.2(1.8)$ & $0.9(1.5)$ & & & $0.001^{\mathrm{b}}$ & \\
\hline B $v s \mathrm{C}$ & & & & -1.8 & 0.4 & $<0.001^{\mathrm{a}}$ & $<0.001^{\mathrm{c}}$ \\
\hline B $v s \mathrm{~L}$ & & & & -1.3 & 0.4 & $0.02^{\mathrm{a}}$ & $0.02^{\mathrm{c}}$ \\
\hline $\mathrm{C} v s \mathrm{~L}$ & & & & 0.5 & 0.4 & $>0.99^{\mathrm{a}}$ & $>0.99^{c}$ \\
\hline $24 \mathrm{hr}$ & $0.7(1.3)$ & $1.2(1.2)$ & $0.6(1.1)$ & & & $0.12^{\mathrm{b}}$ & \\
\hline $\mathrm{B} v s \mathrm{C}$ & & & & -0.9 & 0.3 & $>0.99^{\mathrm{a}}$ & $>0.99^{c}$ \\
\hline $\mathrm{B} v s \mathrm{~L}$ & & & & -0.6 & 0.3 & $0.44^{\mathrm{a}}$ & $0.35^{\mathrm{c}}$ \\
\hline $\mathrm{C} v s \mathrm{~L}$ & & & & -0.5 & 0.3 & $0.86^{\mathrm{a}}$ & $0.65^{\mathrm{c}}$ \\
\hline
\end{tabular}

Values are expressed as mean (SD)

${ }^{\text {a }} P$ value, analysis of multiple pairwise comparisons by applying the Bonferroni correction. $P$ values were multiplied by three for the adjustment of pairwise comparisons

${ }^{\mathrm{b}} P$ value, analysis of multiple comparisons. $P$ values were multiplied by four, according to the time-period, for the adjustment

c $P$ value, analysis of multiple pairwise comparisons by applying the Tukey correction. $P$ values were multiplied by three for the adjustment of pairwise comparisons

Caution: The outliers contained in this data may affect interpretation of results

Group C: spraying normal saline as a control group

Group L: spraying $10 \%$ lidocaine hydrochloride

Group B: spraying $0.3 \%$ benzydamine hydrochloride

$\mathrm{PACU}=$ postanesthetic care unit; $\mathrm{POST}=$ postoperative sore throat; $\mathrm{SD}=$ standard deviation

administration per os. The study authors concluded that local application of $\mathrm{BH}$ prevented a systemic adverse reaction. $^{23}$ In addition, $\mathrm{BH}$ applied directly into the oropharyngeal cavity was associated with a higher incidence of adverse effects including local numbness, stinging, and burning sensation. ${ }^{10}$ Our mode of application for $\mathrm{BH}$ might have resulted in a small amount of systemic absorption and reduced the incidence of systemic side effects.

Tanaka et al. reported that lidocaine reduced the risk of POST; in some studies, the mechanism is known to attenuate the excitement of sensory $\mathrm{C}$ fibres and to inhibit the release of sensory neuropeptides involving excitation of sensory $\mathrm{C}$ fibres in the airway. ${ }^{24}$ Nevertheless, they also mentioned that the effects of lidocaine are influenced by route of administration, drug concentration, and type of study subjects. In previous research, the administration of $8 \%$ or $10 \%$ lidocaine spray to the larynx, trachea, or ETT increased the incidence of POST to varying degrees. 9,23
Our study showed similar results at $24 \mathrm{hr}$. The authors explained that the throat ailments associated with lidocaine spray were probably related to the additives, which can irritate the tracheal mucosa ${ }^{9,25}$; notably, the dose of lidocaine applied in the study by Hung et al. ${ }^{9}$ was larger than that used in our study (ten $v s$ three sprays). Importantly, as $10 \%$ lidocaine spray is currently used for endoscopy or awake endotracheal intubation, its application requires close attention.

This study has several limitations. First, the sample size was calculated to determine the statistical difference in incidence of POST among the three groups, and there was not a reduction in incidence in relation to $\mathrm{BH}$. The small sample size could affect the incidence of POST and prevalence of side effects in the subjects. Second, some patients may have been confused and unable to distinguish POST from surgical region pain because of the proximity of the throat to the surgical site in the neck. To avoid such confusion as much as possible, we explained to the patients 
the different characteristics of surgical pain and POST before asking about pain. Third, we sprayed normal saline onto the ETT cuff as a control. Nevertheless, in clinical practice, we do not use a spray on the ETT cuff. Therefore, the POST symptoms in the control group might be lower because of the moisturizing effect. Even though Jung et al. reported that humidification of anesthetic gas reduced sore throat after thyroidectomy, they used an active humidifier throughout the surgery, which was different from the method and duration of exposure in the normal saline group in our study. ${ }^{26}$ Finally, we could not establish the optimal dose of topical BH applied to the ETT cuff as a prophylactic agent to attenuate POST. Nevertheless, in a recent meta-regression analysis, the authors found no association of dose with effect size. ${ }^{15}$ No subjects in this study had side effects associated with the $\mathrm{BH}$ spray, which contained approximately $0.9 \mathrm{mg}$ of $\mathrm{BH}$.

In conclusion, application of BH spray on the ETT cuff reduced the incidence and severity of POST at $12 \mathrm{hr}$ after TT compared with $10 \%$ lidocaine and normal saline. Although these effects of $\mathrm{BH}$ did not appear at all time points, we suggest that a $\mathrm{BH}$ spray is a non-invasive and effective method of treating POST without serious side effects. In addition, 10\% lidocaine must be applied with attention. Further research is warranted to determine whether POST can be ameliorated by other methods.

\section{Conflicts of interest None declared.}

Editorial responsibility This submission was handled by Dr. Gregory L. Bryson, Deputy Editor-in-Chief, Canadian Journal of Anesthesia. Dr. Bryson identified the retrospective registration of this trial after accepting the manuscript. He regrets this deviance from Journal policy.

Author contributions Doyeon Kim participated in design and conduct of the study, data collection, data analysis, and manuscript preparation. Heejoon Jeong contributed to protocol design, data collection, data analysis, and writing the manuscript. Jihye Kwon contributed to the acquisition of data. Sehee Kang and Bobae Han contributed to the analysis of data. Eun Kyung Lee contributed to the interpretation of data. Sangmin M. Lee contributed to the conception and design of the study. Ji Won Choi contributed to all aspects of this study, including conception and design; acquisition, analysis, and interpretation of data, and drafting the article.

Funding No funding agency in the public, commercial, or not-forprofit sector provided a specific grant for this trial.

\section{References}

1. Peppard SB, Dickens $J H$. Laryngeal injury following short-term intubation. Ann Otol Rhinol Laryngol 1983; 92: 327-30.

2. Biro P, Seifert B, Pasch T. Complaints of sore throat after tracheal intubation: a prospective evaluation. Eur $\mathrm{J}$ Anaesthesiol 2005; 22: 307-11.
3. McHardy FE, Chung F. Postoperative sore throat: cause, prevention and treatment. Anaesthesia 1999; 54: 444-53.

4. Christensen AM, Willemoes-Larsen H, Lundby L, Jakobsen KB. Postoperative throat complaints after tracheal intubation. $\mathrm{Br} \mathrm{J}$ Anaesth 1994; 73: 786-7.

5. Sanou J, Ilboudo D, Rouamba A, Traore O. Sore throat after tracheal intubation (French). Cah Anesthesiol 1996; 44: 203-6.

6. Hisham AN, Roshilla H, Amri N, Aina EN. Post-thyroidectomy sore throat following endotracheal intubation. ANZ J Surg 2001; 71: 669-71.

7. Ryu JH, Han SS, Do SH, Lee JM, Lee SC, Choi ES. Effect of adjusted cuff pressure of endotracheal tube during thyroidectomy on postoperative airway complications: prospective, randomized, and controlled trial. World J Surg 2013; 37: 786-91.

8. Quane PA, Graham GG, Ziegler JB. Pharmacology of benzydamine. Inflammopharmacology 1998; 6: 95-107.

9. Hung NK, Wu CT, Chan SM, et al. Effect on postoperative sore throat of spraying the endotracheal tube cuff with benzydamine hydrochloride, 10\% lidocaine, and 2\% lidocaine. Anesth Analg 2010; 111: 882-6.

10. Huang YS, Hung NK, Lee MS, et al. The effectiveness of benzydamine hydrochloride spraying on the endotracheal tube cuff or oral mucosa for postoperative sore throat. Anesth Analg 2010; 111: 887-91.

11. Chang JE, Min SW, Kim CS, Han SH, Kwon YS, Hwang JY. Effect of prophylactic benzydamine hydrochloride on postoperative sore throat and hoarseness after tracheal intubation using a double-lumen endobronchial tube: a randomized-controlled trial. Can J Anesth 2015; 62: 1097-103.

12. Mekhemar NA, El-Agwany AS, Radi WK, El-Hady SM. Comparative study between benzydamine hydrochloride gel, lidocaine $5 \%$ gel and lidocaine $10 \%$ spray on endotracheal tube cuff as regards postoperative sore throat. Braz J Anesthesiol 2016; 66: 242-8.

13. Agarwal A, Nath SS, Goswami D, Gupta D, Dhiraaj S, Singh PK. An evaluation of the efficacy of aspirin and benzydamine hydrochloride gargle for attenuating postoperative sore throat: a prospective, randomized, single-blind study. Anesth Analg 2006; 103: 1001-3.

14. Kuriyama A, Aga M, Maeda $H$. Topical benzydamine hydrochloride for prevention of postoperative sore throat in adults undergoing tracheal intubation for elective surgery: a systematic review and meta-analysis. Anaesthesia 2018; 73: 889900.

15. Estebe JP, Gentili M, Le Corre P, Dollo G, Chevanne F, Ecoffey $C$. Alkalinization of intracuff lidocaine: efficacy and safety. Anesth Analg 2005; 101: 1536-41.

16. Branson RD, Campbell RS, Davis K, Porembka DT. Anaesthesia circuits, humidity output, and mucociliary structure and function. Anaesth Intensive Care 1998; 26: 178-83.

17. Kuriyama A, Maeda $H$, Sun $R$, Aga M. Topical application of corticosteroids to tracheal tubes to prevent postoperative sore throat in adults undergoing tracheal intubation: a systematic review and meta-analysis. Anaesthesia 2018; 73: 1546-56.

18. Renner B, Ahne G, Grosan E, Kettenmann B, Kobal G, Shephard $A$. Tonic stimulation of the pharyngeal mucosa causes pain and a reversible increase of inflammatory mediators. Inflamm Res 2013; 62: 1045-51.

19. Vane $J R$. Inhibition of prostaglandin synthesis as a mechanism of action for aspirin-like drugs. Nat New Biol 1971; 231: 232-5.

20. Sawynok J. Topical and peripherally acting analgesics. Pharmacol Rev 2003; 55: 1-20.

21. Sironi $M$, Pozzi P, Polentarutti N, et al. Inhibition of inflammatory cytokine production and protection against endotoxin toxicity by benzydamine. Cytokine 1996; 8: 710-6. 
22. Guglielmotti A, Aquilini L, Rosignoli MT, et al. Benzydamine protection in a mouse model of endotoxemia. Inflamm Res 1997; 46: $332-5$.

23. Baldock GA, Brodie RR, Chasseaud LF, Taylor T, Walmsley LM, Catanese $B$. Pharmacokinetics of benzydamine after intravenous, oral, and topical doses to human subjects. Biopharm Drug Dispos 1991; 12: 481-92.

24. Chang $A B$. Cough, cough receptors, and asthma in children. Pediatr Pulmonol 1999; 28: 59-70.

25. Hara $K$, Maruyama $K$. Effect of additives in lidocaine spray on postoperative sore throat, hoarseness and dysphagia after total intravenous anaesthesia. Acta Anaesthesiol Scand 2005; 49: 4637.

26. Jung TH, Rho JH, Hwang JH, Lee JH, Cha SC, Woo SC. The effect of the humidifier on sore throat and cough after thyroidectomy. Korean J Anesthesiol 2011; 61: 470-4.

Publisher's Note Springer Nature remains neutral with regard to jurisdictional claims in published maps and institutional affiliations. 